\title{
Surface Morphology Analysis of GaInAsSb Films Grown by Liquid Phase Epitaxy
}

\author{
L. Tirado-Mejía*, J. G. Ramírez ${ }^{\dagger}$, M. E. Gómez ${ }^{\dagger}$, and H. Ariza-Calderón* \\ *Laboratorio de Optoelectrónica, Universidad del Quindio, Armenia-Colombia A.A. 460 \\ $\dagger$ Thin Films Group, Universidad del Valle, A.A. 25360 Cali-Colombia
}

\section{Received on 8 December, 2005}

\begin{abstract}
We studied growth mechanisms in semiconducting $\mathrm{Ga}_{1-x} \mathrm{In}_{x} \mathrm{As}_{y} \mathrm{Sb}_{1-y}$ films grown by liquid phase epitaxy on (100) GaSb:Te $\left(10^{17} \mathrm{~cm}^{-3}\right)$ substrates at $600{ }^{\circ} \mathrm{C}$ solution-substrate temperature. Atomic Force Microscopy (AFM) images of these films show step-like corrugations, undulations, grooves, and terraces. The terraces are a few $\mathrm{nm}$ in height and hundreds of nanometers in length. Epitaxial $\mathrm{Ga}_{1-x} \mathrm{In}_{x} \mathrm{As}_{y} \mathrm{Sb}_{1-y}$ films grow latticematched to the (100) GaSb substrates. These narrow-gap quaternary $\mathrm{Ga}_{1-x} \mathrm{In}_{x} \mathrm{As}_{y} \mathrm{Sb}_{1-y}$ compounds are suitable materials for heterostructure devices operating in the infrared wavelength range. The estimated $x$ and $y$ values are in the GaSb-rich zone. The step-like corrugations (bunching steps) are formed by different mechanisms, such as pinning effect probably due to impurities on the substrate surface.
\end{abstract}

Keywords: Liquid phase epitaxy; Surface structure; Quaternary semiconductors

\section{INTRODUCTION}

Narrow-gap quaternary $\mathrm{Ga}_{1-x} \mathrm{In}_{x} \mathrm{As}_{y} \mathrm{Sb}_{1-y}$ compounds are particularly attractive for the fabrication of a wide variety of optoelectronic devices, such as light emitting diodes, laser diodes, photo detectors, and thermo photovoltaic (TPV) devices operating in the mid-infrared wavelength range. TPV cells appear as attractive choices for electrical production. The low-band gap III-V antimony-based semiconductors are also considered suitable materials as radiator converters, due to their working range temperature and efficiency [1]. Indeed, ternary and quaternary antimony-based alloys are preferable for such applications, given the flexible change of the band gap, as well as the lattice constant, which can be tuned by simple modification of the chemical stoichiometric of the compounds. For this reason, they are also useful materials for low refractive index coating layers in $\mathrm{GaSb} / \mathrm{GaInAsSb} / \mathrm{GaAlAsSb}$ lasers and LEDs.

Among many techniques to grow $\mathrm{Ga}_{1-x} \mathrm{In}_{x} \mathrm{As}_{y} \mathrm{Sb}_{1-y}$ epitaxial layers on GaSb substrates, Liquid Phase Epitaxy (LPE) still remains an attractive method due to its simplicity. But the existence of a large miscibility gap [2] hinders the growth of $\mathrm{Ga}_{1-x} \mathrm{In}_{x} \mathrm{As}_{y} \mathrm{Sb}_{1-y}$ in a wide range of $x$ and $y$ values. It is considered a metastable alloy, with the tendency to decompose into regions of non-uniform alloy composition. It should be noted that, owing to the large unstable region, only GaSbenriched solid solution compositions will be stable at typical LPE temperatures with lattice-matching to GaSb substrate [3]. Thus is why trying to reduce the band gap of the quaternary antimonide material for the desired value for TPV applications, usually results in phase separations.

Macroscopically, heat, mass transport, and morphological stability are factors involved in the coupling among complex interfacial processes in the precursor solution, given their mutual interaction. To understand the kinetics of growth, we need to microscopically observe surface morphology. It is crucial to control the behavior and surface features to effectively design electronic devices, using epitaxial semiconducting multilayer $[4,5]$.

Atomic Force Microscopy (AFM) is a technique to study surface structures of multilayered films, and such is capable of high, vertical resolution that can be applied to the ex-situ observation of the surface morphology of materials. It allows the study of growth processes, mechanisms, and driving forces responsible for surface structures and defects. Understanding the processes governing the movement of adsorbed atoms among neighboring surface steps is still an unanswered question of fundamental interest in surface science.

Herein, we present interesting features of film surfaces of the quaternary alloy $\mathrm{Ga}_{1-x} \operatorname{In}_{x} \mathrm{As}_{y} \mathrm{Sb}_{1-y}$, with $x$ and $y$ concentrations in the GaSb-enriched solid solution compositions. The films were grown via liquid phase epitaxy on singlecrystal (100) oriented GaSb:Te $\left(10^{17} \mathrm{~cm}^{-3}\right)$ substrates with substrate temperature at $600{ }^{\circ} \mathrm{C}$, only varying deposition times.

AFM images of the films show surface undulations, bunching steps, and flat terraces characteristic of samples grown via LPE [6]. Quantitative analysis of AFM images permits the correlation of layer deposition time with the size of the elemental steps, humps, and terraces.

\section{EXPERIMENTAL PROCEDURE}

$\mathrm{Ga}_{1-x} \mathrm{In}_{x} \mathrm{As}_{y} \mathrm{Sb}_{1-y}$ layers were grown by liquid phase epitaxy. In general, group III elements (Ga, In) are used as solvents and the solution is saturated by group V elements (As, $\mathrm{Sb})$. Growth is conducted by decreasing temperature until the solute diffuses into the solution. For the (100) GaSb:Te $\left(10^{17}\right.$ $\mathrm{cm}^{-3}$ ) substrates, anions $\mathrm{As}$ and $\mathrm{Sb}$ are incorporated to the growing layer together with the cations $\mathrm{Ga}$ and In to form the III-V compound.

LPE growth was performed on a quartz reactor tube heated by a three-zone furnace. Single-phase growth solutions were prepared from $6 \mathrm{~N}$ In, Ga, Sb, and from undoped GaAs under a purified hydrogen atmosphere in a conventional horizontal graphite boat. The substrates were etched by chemical etching performed with a $\mathrm{Na}_{2} \mathrm{~S}$ solution, followed by an in-situ thermal treatment to eliminate the sulphide layer formed upon the substrate surface. 
Growth temperature for the set of samples was $600{ }^{\circ} \mathrm{C}$. The samples were grown by varying deposition times between 90 and $240 \mathrm{~s}$. (Table I), and keeping other growth parameters fixed.

Table I. Set of GaInAsSb samples.

\begin{tabular}{|c|c|c|}
\hline Sample & Growth Temp $\left({ }^{\circ} \mathrm{C}\right)$ & Contact Time (s) \\
\hline 1 & 600 & 90 \\
\hline 2 & 600 & 120 \\
\hline 3 & 600 & 150 \\
\hline 4 & 600 & 240 \\
\hline
\end{tabular}

AFM images were obtained in the contact mode (set point forces 1-10 $\mathrm{nN}$ ) by using a Park Scientific Instrument AF Microscope $^{\mathrm{TM}}$. This technique is able to scan relatively large surfaces (several microns) of a film with sub nanometer resolution in the z-direction. We can also obtain 2- and 3dimensional images with sizes $\mathrm{L}^{2}$ from 1 to $25 \mu \mathrm{m}^{2}$.

The stoichiometric of the samples was estimated by EDS measurements [7]. In and As concentration values are about $14 \%$ to $17 \%$ atomic concentration of cations, and $13 \%$ to $16 \%$ atomic concentration of anions, respectively. The relationship between $x$ and $y$ obeys the GaSb lattice matched condition ( $y$ $=0.91 x)[8]$.

\section{RESULTS AND DISCUSSION}

The samples were characterized through optical property analysis at low temperatures, revealing the energy range of the optical response in photoluminescence and photoreflectance measurements that agree with energy values of the quaternary compound, as reported by other authors $[9,10]$.

The literature widely discusses the occurrence of different phases on $\mathrm{Ga}_{1-x} \mathrm{In}_{x} \mathrm{As}_{y} \mathrm{Sb}_{1-y}$ epitaxial films during growth, due to the decomposition in binary compounds resulting from the instability of the quaternary alloy, for $x$ and $y$ values, into the miscibility gap. Compared to the analysis presented by Amariei et al. [1], in the images of our sample films, there is no evidence of the presence of two different phases. The AFM images were taken $e x$-situ when strain release has occurred.

Typical surface features for our series of samples, grown from solutions with similar concentrations and different deposition times (a.: 90s, b: 120s, c: 150s, d: 240s) between the substrate and the liquid solution are shown in Figure 1. The main structures observed are: step-like corrugations, undulations, grooves, and terraces. The sample with the lowest deposition time (the thinnest one) does not reveal notable groove formation, evident in the samples with higher deposition times. The undulation hump width is greater in sample $b$ than in the samples with higher deposition times.

We sketched in Fig. 2 the morphology observed. The grooves have an undulation (dashes) with a width $\mathrm{L}_{g}$ and height $\mathrm{H}_{g}$; the terraces have a corrugation (filled line) with a size $\mathrm{L}_{s}$ and height $\mathrm{H}_{s}$. In Fig. 1b, line $\mathrm{A}$ (red line) we indicate the hump width $\mathrm{L}_{g}$.
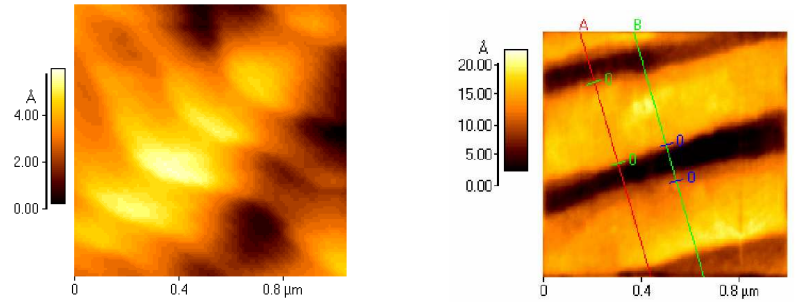

a.

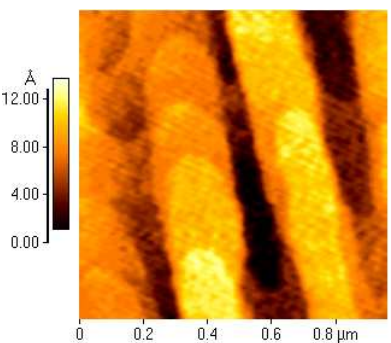

b.

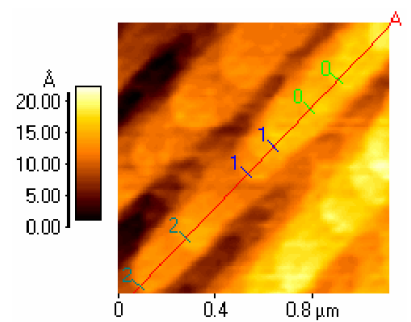

d.

FIG. 1: AFM images for samples grown at the same substrate temperature and varying deposition times: (a) $90 \mathrm{~s}$, (b) $120 \mathrm{~s}$, (c) $150 \mathrm{~s}$, (d) $240 \mathrm{~s}$. Size is the same for all images, $1 \mathrm{x} 1 \mu \mathrm{m}^{2}$.

The values $\left(\mathrm{L}_{g}, \mathrm{H}_{g} \mathrm{~L}_{s}, \mathrm{H}_{s}\right)$ obtained from these images are presented in Table II. The statistical error bar shown in Table II is related to the average between the maximum and minimum values for the measured heights.

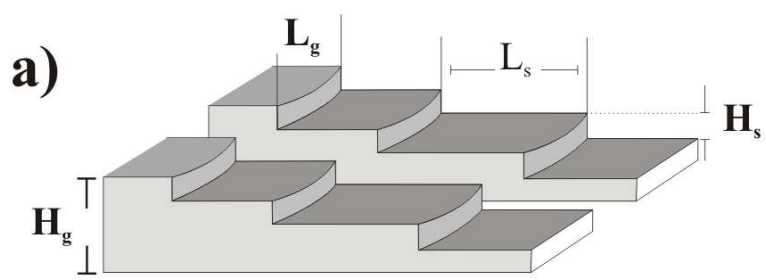

b)

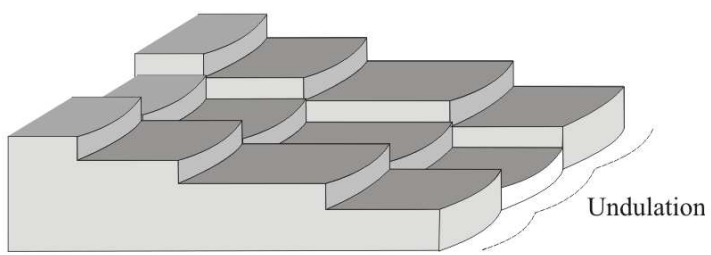

FIG. 2: Sketch of the two stages of the growth mechanisms.

Additionally, in the first stages of growth (lowest deposition time) undulations are not well defined, as observed in Fig. 1a, but these humps and grooves are enhanced as deposition time increases. The main structures presented in Fig. 1a are terraces with atomic step heights. Even if in Fig. 1b they are not clearly observed, for longer growth times (Fig. 1c and 1d) these terraces become flatter. Also, the " $S$ " shape is 
what we term as corrugated surfaces - shown in Figs. 1c. and 1d., corresponding to the way the steps in the terraces move. The three-dimensional image in Fig.3 reveals the "S" shape limiting the terraces and joining the humps. The " $\mathrm{S}$ " shape is perhaps due to the presence of a critical thickness evident when strain is relaxed on the film.

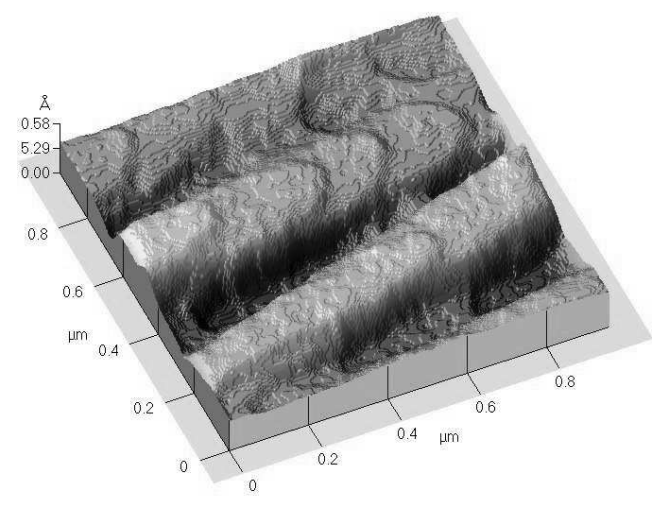

FIG. 3: Three-dimensional AFM image for sample 3 grown with deposition time of $150 \mathrm{~s}$.

As per these undulations, some authors [11] have established a correlation between the mentioned feature and the substrate misorientation. The misorientation of the commercial substrates used for our samples is in the order of $0.1^{\circ}$, a typical misorientation angle, sufficient to give rise to the generation of these humps and grooves [12].

Table II. Characteristic values of AFM images of GaInAsSb films

\begin{tabular}{|l|l|l|l|l|}
\hline $\begin{array}{l}\text { Sample } \\
\text { Name }\end{array}$ & $\begin{array}{l}\mathrm{L}_{g}(\mu \mathrm{m}) \\
\pm \quad 0.03\end{array}$ & $\begin{array}{l}\mathrm{H}_{g}(\AA) \\
\pm 0.2\end{array}$ & $\begin{array}{l}\mathrm{L}_{s}(\mu \mathrm{m}) \\
\pm 0.03\end{array}$ & $\begin{array}{l}\mathrm{H}_{s}(\AA) \\
\pm \quad 0.2\end{array}$ \\
\hline 1 & 0.81 & - & 0.30 & $2.1-3.1$ \\
\hline 2 & 0.46 & $10.2-12.9$ & - & - \\
\hline 3 & 0.25 & $8.0-9.7$ & 0.30 & $2.3-3.3$ \\
\hline 4 & 0.29 & 10.5 & 0.15 & $2.2-3.7$ \\
\hline
\end{tabular}

Under these results, we can argue that the driving force responsible for the atomic steps and terraces is the minimizing of energy of the ad-atoms in the step positions of the misoriented substrates. The terraces are not flat and their edges are slightly higher than the rest of the surface due to the tendency of the ad-atoms to pile up at the edges $[13,14]$.

The epitaxy growth mechanism could be analyzed according to the Stranski-Kastanow (SK) type [15], in which initially the deposition follows a layer-by-layer growth; subsequently, when film thickness reaches a certain critical value, the layer undergoes a two-dimensional to three-dimensional transition. The 3-D growth, forming the " $\mathrm{S}$ " shapes, undulations, and terraces leads to a sharp decrease of the system's total energy, thereby relaxing the strain energy.
Fig. 4 shows the surface morphology for sample 4, grown with deposition time of $240 \mathrm{~s}$.
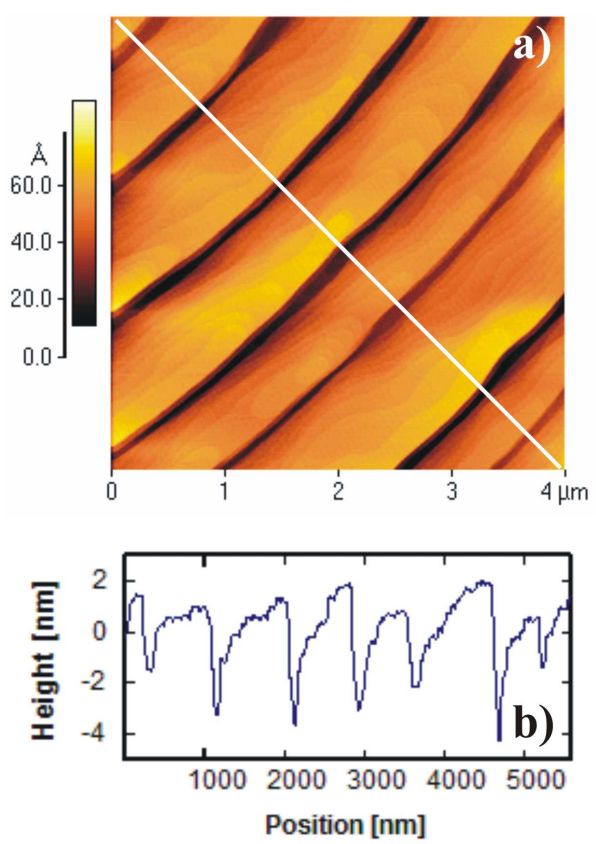

FIG. 4: a) AFM image of sample 4 grown with deposition time of $240 \mathrm{~s}$. b) Height profiles for the line shown in a).

The image shows a wider area, $4 \times 4 \mu \mathrm{m}^{2}$, than that shown in Fig. 1d. The height profile for the line shown in Fig. 4a is shown in Fig. 4b. The steps detailed in the profile image in Fig. $4 \mathrm{~b}$ represent the terrace heights that are between 0.2 and $0.8 \mathrm{~nm}$ with widths around $60 \mathrm{~nm}$. Hump heights were in the average of $3 \mathrm{~nm}$.

Another observation is that the height profile reveals an asymmetric shape of the undulations in the plane perpendicular to the substrate surface. This behavior, described by Nishinaga et al, [12] means that the humps move slowly, while film growth occurs covering the whole terrace areas. We can generally conclude that the atomic steps of the terraces propagate along the humps.

A factor responsible for step bunching is the presence of impurities. The step bunching produced by impurities could be formed due to a pinning mechanism in which impurities fixed on the crystal surface prevent step advancement, and the decrease of active kink sites by occupation of impurities. Fig. 5 shows terraces interfering with an obstacle in sample $1(90$ $\mathrm{s}$ deposition time). As the terrace arrived to the impurity, it bends around the obstacle on both sides forming an almost circular terrace. The perturbation is propagated to some terraces in the vicinity, forming step bunching. Figure 5 shows the pinning effect. 


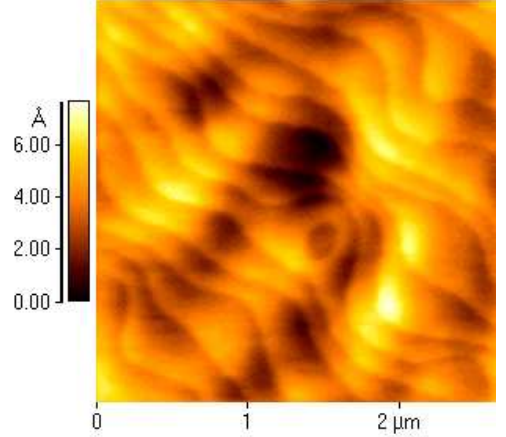

FIG. 5: AFM image for sample 1 (deposition time of $90 \mathrm{~s}$ ) showing pinning effect. Image size is $2.5 \times 2.5 \mu \mathrm{m}^{2}$.

\section{CONCLUSIONS}

A quaternary semiconductor GaInAsSb system was grown on monocrystal substrates by the LPE technique at $600{ }^{\circ} \mathrm{C}$ substrate temperature. Surface morphology was analyzed by using Atomic Force Microscopy. The GaInAsSb films displayed typical surface structures of the LPE technique. The morphology revealed step-like corrugations, undulations, grooves, and terraces. One feature is the formation of undulations, corrugations, and atomic steps, and another is the pinning effect, indicating two independent mechanisms for the step bunching formation. Those structures are strongly related to substrate misorientation and to the Stranski-Kastanow growth type. The values obtained for the atomic heights are in the range of 0.2 to $0.8 \mathrm{~nm}$; hump heights are around $3 \mathrm{~nm}$, terrace lengths are in the order of hundreds of nanometers, and hump widths are in the order of 0.2 to $0.8 \mu \mathrm{m}$.

\section{Acknowledgement}

This work was supported by COLCIENCIAS project No. 1113-05-11441, Universidad del Quindío; Excellence Center for Novel Materials (ECNM) under contract 0043-2005, and research project "Quantitative Determination of Interfacial Roughness Parameters in Layers and Multilayers Through Statistical Analysis of Digitized AFM Images", code 7681-05.
[1] A Amariei, E.K. Polychroniadis, F. Dimroth, and A.W. Bett, J. Cryst. Growth 275, 229 (2005).

[2] Nakajima, Osamura, Yasuda y Murakami, J. Cryst. Growth 41, 87 (1977).

[3] J.L. Lazzari, E. Tournié, F. Pitard, and A. Joullié, Mat. Scie. and Eng. B 9, 125 (1991).

[4] C.C. Hsu, T.K.S. Wong, and I.H. Wilson, Appl. Phys. Lett. 63, 1839 (1993).

[5] B.J. Gibbons, J. Noffsinger, and J.P. Pelz, Surf. Scien. 575, L51 (2005).

[6] F. Kawamura, T. Takahashi, F. Utsuno, and I. Yasui, J. Cryst. Growth 244, 173 (2002).

[7] GES, ICMUV, Universitat de Valencia, Spain.

[8] K. Shim, H. Rabitz, and P. Dutta, J. Appl. Phys. 88, 7157 (2000).
[9] S. Iyer, S. Hegde, Ali Abul-Fadl, K. K. Bajaj, and W. Mitchel, Phys. Rev. B 47, 1329 (1993).

[10] C.A. Wang, D.R. Calawa, and C.J. Vineis, J. Cryst. Growth 225, 377 (2001).

[11] E. Bauser, M. Frik, K.S. Loechner, L. Schmidt, and R. Ulrich, J. Cryst. Growth 27, 148 (1974).

[12] T. Nishinaga, J. Cryst. Growth 274, 19 (2005).

[13] K. Pak, T. Nishinaga, and T. Nakamura, J.J. Appl. Phys. 18, 1699 (1979)

[14] M.G. Astles, H. Hill, and V.W. Steward, J. Cryst. Growth 62, 61 (1983)

[15] J. Sen, P. JIn, Z.G. Wang, H.Z. Zhang, Z.Y. Wang, and L.Z. Hu, Thin Solid Films 476, 68 (2005). 